\title{
Thirty-year follow-up after extracranial-intracranial bypass surgery
}

\author{
Case report
}

\author{
O. Howard Reichman, M.D., Edward A. M. Duckworth, M.D., M.S., \\ Douglas E. Anderson, M.D., and Thomas C. Origitano, M.D., Ph.D.
}

Department of Neurological Surgery, Stritch School of Medicine, Loyola University Medical Center, Maywood, Illinois

\begin{abstract}
$\checkmark$ The conventional wisdom resulting from the international, multicenter, trial of extracranial-intracranial bypass surgery is that this procedure offers no benefit. Because of the complex and unique circumstances of some, clinical experience and judgment must sometimes overrule some statistical conclusions. (DOI: 10.3171/FOC/2008/24/2/E19)
\end{abstract}

\author{
KEY WORDS • cerebral ischemia \\ extracranial-intracranial bypass
}

$\mathrm{T}$ $\mathrm{HE}$ international, multicenter, randomized trial of EC-IC bypass surgery published in 1985 was of significant value. ${ }^{1}$ Too many procedures have been performed by individuals with little expertise in patient selection or inadequate surgical skill. However, as each patient has clearly recognizable physical features, we all face unique risks. The threat of severe disability or even death as the result of cerebrovascular insufficiency should be significantly reduced or eliminated in certain persons by the creation of new collateral circulation to the brain. We describe such a case.

\section{Case Report}

History and Examination. This 13-year-old boy was walking home from school in Berkeley, Illinois, on a cold, snowy afternoon (November 21, 1977) when he suddenly developed a right-sided headache, and his friend noticed that he had become confused and unsteady. He then fell to the ground and was thought to be unconscious. He was immediately taken to a local hospital and was transferred to Loyola University Medical Center. On examination he was found to be stuporous and incoherent. A left hemiparesis involved his face and upper and lower extremities.

An arteriogram was obtained the next day and demonstrated complete occlusion of the right ICA above the common carotid bifurcation with some filling of the ECA and its branches and, through some reflux into the innominate artery, some filling of the right vertebrobasilar system (Fig.

Abbreviations used in this paper: $\mathrm{EC}-\mathrm{IC}=$ extracranial-intracranial; ECA = external carotid artery; ICA = internal carotid artery; $\mathrm{MCA}=$ middle cerebral artery; STA = superficial temporal artery.
1). A left carotid artery injection demonstrated normal filling of the left middle cerebral system and both left and right anterior cerebral branches. There was also cross-filling into the right anterior cerebral artery retrograde toward the right internal carotid bifurcation, where it was totally blocked (Fig. 2).

Operation. On November 23, 1977, an anastomosis was performed between the right STA and an MCA branch. During surgery a thrombus was observed near 1 of the branches of the MCA. The postoperative course was smooth and uneventful with gradual improvement of the left hemiparesis.

Postoperative Course. In January 1978 the patient experienced a minor ischemic event and on February 9, 1978, a follow-up angiogram was obtained. This again demonstrated complete occlusion of the right ICA, but the bypass was irrigating the entire MCA territory (Figs. 3 and 4). Later views demonstrated rich perfusion, but there remained a tiny drop of contrast material near the trifurcation of the right MCA (Fig. 5).

This patient experienced no further problems and was able to graduate from high school without any difficulty in 1982. He then graduated from trade school in August 1984 (automobile body work). He was employed in road construction with safety signs, detours, and barricades. He went on to attend the Trade School for the Local Trade Union 134 of the International Brotherhood for Electrical Workers (1989-1994) and became a Journeyman. He currently is employed as an electrician, which requires climbing ladders, tedious work in tight spaces, and precise dexterity. His only remaining deficit is very slight limitation of dexterity of his left hand, which he uses to support the most detailed maneuvers of his right hand. 


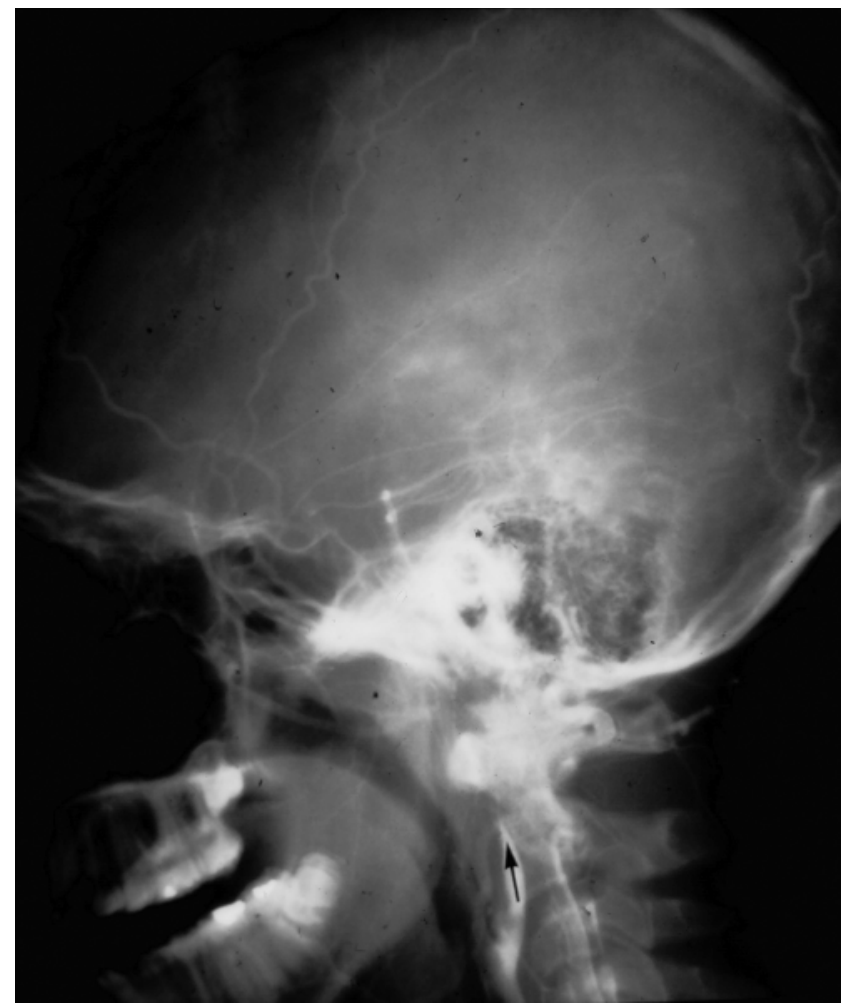

FIG. 1. Preoperative right common carotid arteriogram obtained on November 22, 1977. Complete occlusion of the right ICA (arrow) is seen as well as patent right ECA branches, and a patent vertebrobasilar system, but no posterior communicating artery collateral circulation.

During 1994 this patient provided me with a letter expressing his appreciation for the care he received and summarizing his life experience to the age of 30 years (Fig. 6). On October 18, 2007, it was our privilege to share an enjoyable few moments with the patient and review the past 30 years (Fig. 7). He is now 43 years of age.

\section{Conclusions}

It is our opinion that the operation performed November 23, 1977, saved this patient from some potentially devastating consequences so that he has been able to enjoy a normal life. This opinion cannot be proven, but no one can disprove our opinion. Each person is an individual possessing unique circumstances, so that clinical experience and judgment must overrule statistics in certain patients. ${ }^{1,2}$

\section{References}

1. EC/IC Bypass Study Group: Failure of extracranial-intracranial arterial bypass to reduce the risk of ischemic stroke. Results of an international randomized trial. N Engl J Med 313:1191-1200, 1985

2. Sundt TM Jr: Was the international randomized trial of extracranial-intracranial arterial bypass representative of the population at risk? N Engl J Med 316:814-816, 1987

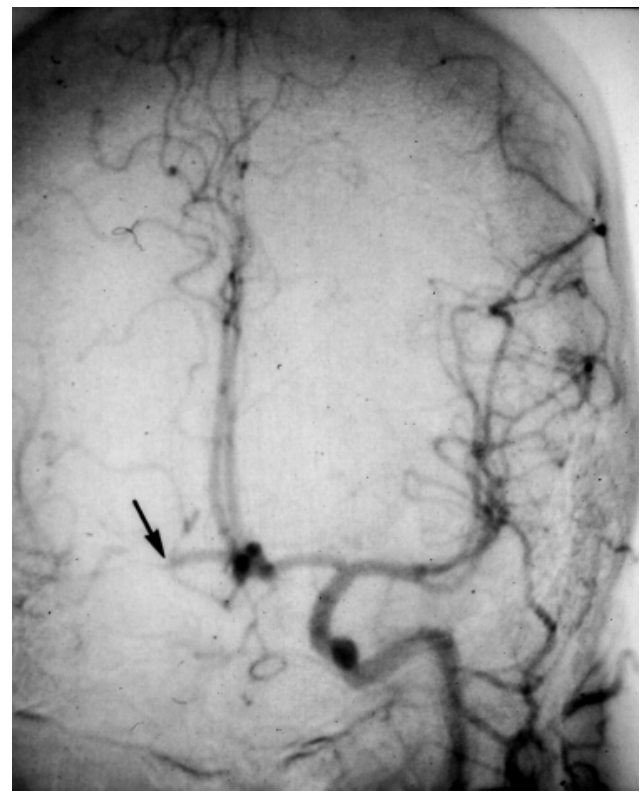

FIG. 2. Preoperative left common carotid arteriogram obtained on November 22, 1977. Normal left middle cerebral perfusion is seen, as well as normal filling of both anterior cerebral arteries and retrograde filling of the right anterior cerebral artery to the occluded right internal carotid bifurcation (arrow).

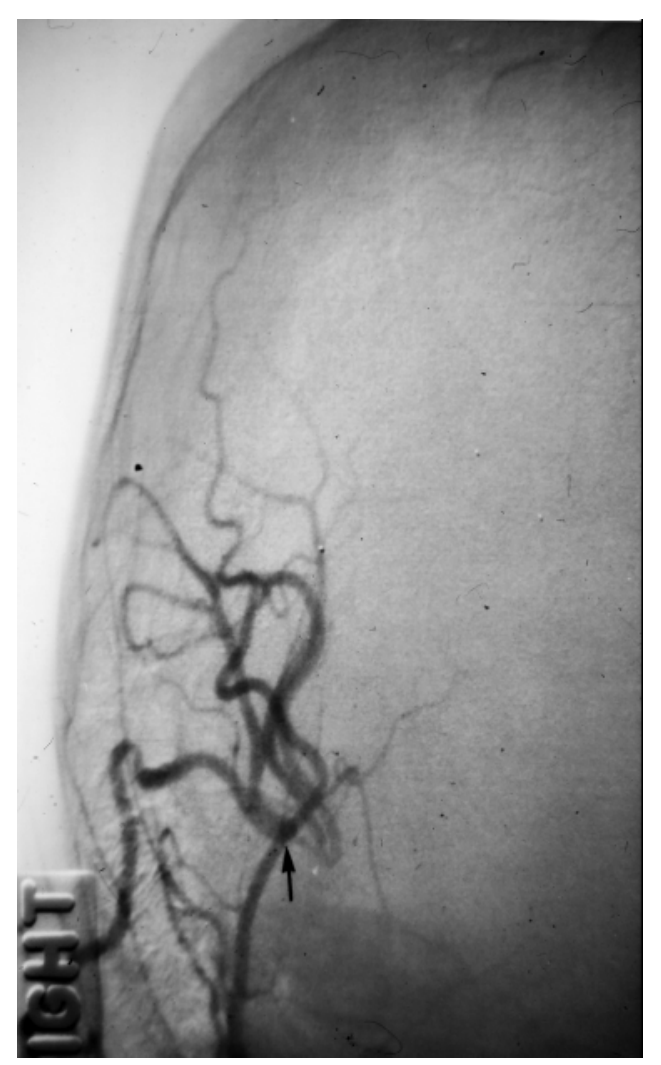

FIG. 3. Postoperative right common carotid arteriogram obtained on February 9, 1978). Early frontal film showing large STA filling right middle cerebral vasculature through anastomosis (arrow). 


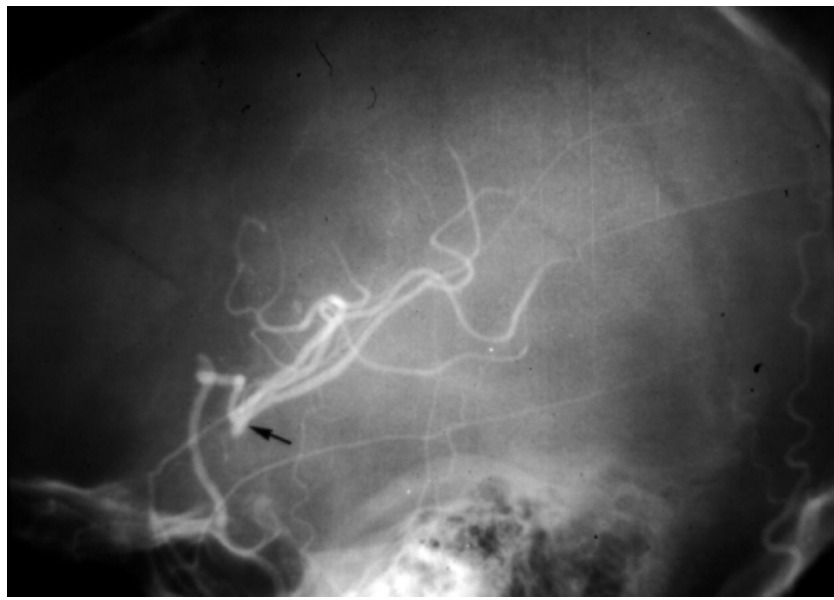

FIG. 4. Postoperative right common carotid arteriogram obtained on February 9, 1987. Early lateral film showing large STA filling right middle cerebral vasculature through anastomosis (arrow).

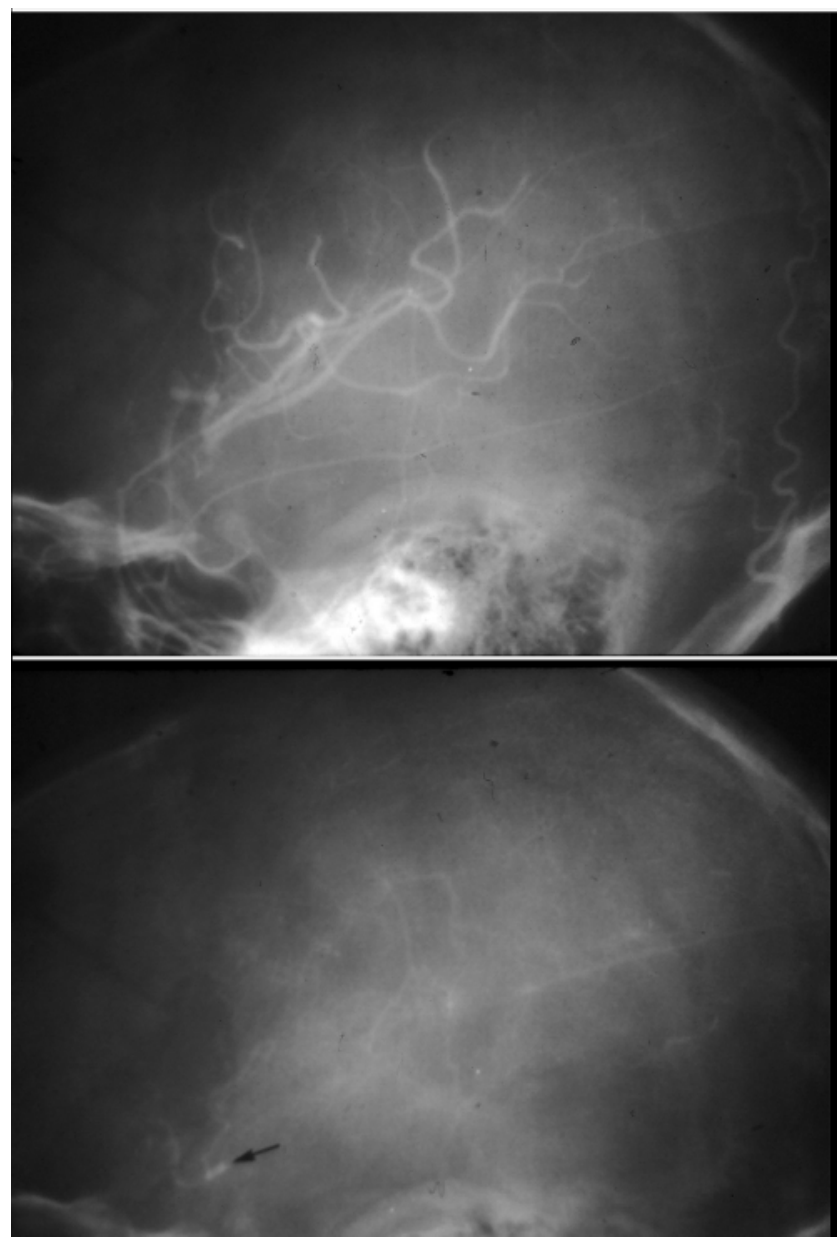

FIG. 5. Later lateral postoperative films obtained on February 9, 1987. Upper: Rich perfusion of the right middle cerebral territory. Lower: A small drop of contrast material near MCA trifurcation (arrow) is seen.

\section{Reichman,}

me but my naine is

$I$ dont know if yodel remepiler was a patiext of vars 17 vedrs ago. $0 \mathrm{~m}$

noremeles 21, 1907, sulfered a hight cerelual infarct, irth paiklyais of my lift side. On thomber 23,1977, upo performed a Right cranitomy on me and semozed a larde thiomles fom the midde cerelizel ateres. I recowired will, with your help, with only minimal weakreso op my lect aus, and lept les remaining. ura 19 yedroold at the time, and mov tm 30 yearsold. $\checkmark$ have licome en electricien, and am alle to do just atout any activity, euen thriglud setill haye a sonall weresnos in suy (b) anm and (b) leg.

In writ thing this letter to thank yow, and to let yow henow, worrgeness is mot frogten. of had made a trip to the maso dince in the sumnew of 1978 , and theis ofreding lore incordelewy as to why thes happened of sincerely thank you for saving my life and allowing me to dile so narang folfuling yearo. With sincere thankes,

FIG. 6. Photograph of a letter of appreciation 17 years (1994) after the EC-IC bypass operation (1977).

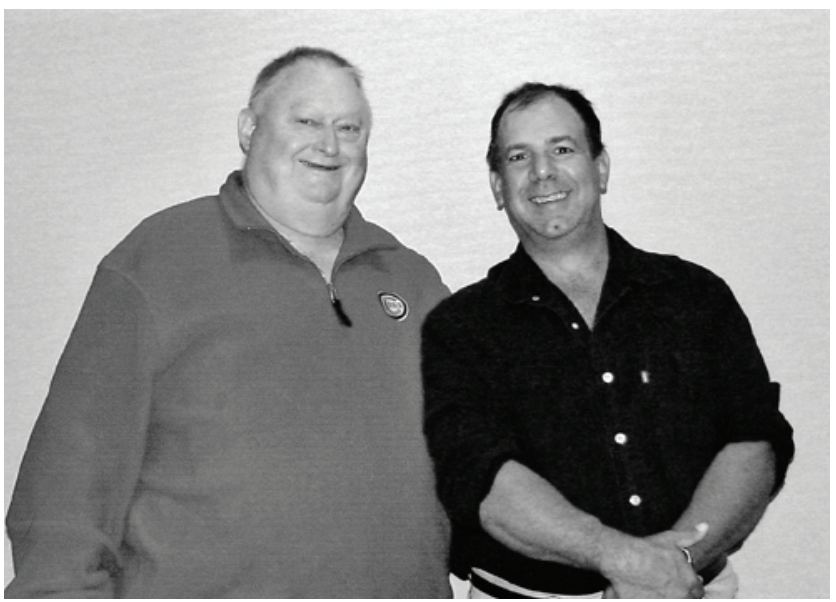

FIG. 7. Photograph of the neurosurgeon (left) and patient at 43 years old (right) obtained on October 18, 2007, almost 30 years after the EC-IC bypass operation.

Manuscript submitted November 15, 2007.

Accepted December 24, 2007.

Address correspondence to: O. Howard Reichman, M.D., 241 West Woodside Drive, Provo, Utah 84604-4422. email: nancy@ reichmanfam.net. 